\title{
Enhancing the Activity of Glucocerebrosidase as a Treatment for Parkinson Disease
}

Elisa Menozzi, MD, Anthony H. V. Schapira, MD, FRCP, DSc, FMedSci

Department of Clinical and Movement Neurosciences, University College London Queen Square Institute of Neurology, London, United Kingdom

\section{Corresponding author:}

Anthony H. V. Schapira

Email address: a.schapira@ucl.ac.uk

Running title: Enhancing Glucocerebrosidase Activity as a Treatment for Parkinson Disease

\begin{abstract}
(217 words)
Mutations in the glucocerebrosidase (GBAl) gene are the most common genetic risk factor for Parkinson disease (PD). Homozygous or compound heterozygous GBAl mutations cause the lysosomal storage disorder Gaucher disease (GD), characterized by deficient activity of the glucocerebrosidase enzyme (GCase). Both individuals with GD type 1 and heterozygous carriers of pathogenic variants of GBAl have an increased risk of developing PD, by approximately 10-20-fold compared to non-carriers. GCase activity is also reduced in PD patients without GBAl mutations, suggesting that the GCase lysosomal pathway might be involved in PD pathogenesis. Available evidence indicates that GCase can affect $\alpha$-synuclein pathology in different ways. Misfolded GCase proteins are retained in the endoplasmic reticulum, altering the lysosomal trafficking of the enzyme and disrupting protein trafficking. Also, deficient GCase leads to accumulation of substrates that in turn may bind $\alpha$-synuclein and promote pathological formation of aggregates. Furthermore, $\alpha$-synuclein itself can lower the enzymatic activity of GCase, indicating that a bidirectional interaction exists between GCase and $\alpha$ synuclein. Targeted therapies aimed at enhancing GCase activity, augmenting the trafficking of misfolded GCase proteins by small molecule chaperones, or reducing substrate accumulation, have been tested in preclinical and clinical trials. This article reviews the molecular mechanisms linking GCase to $\alpha$-synuclein and discusses the therapeutic drugs that by targeting the GCase pathway can influence PD progression.
\end{abstract}

\section{Key points}

- Mutations in the GBAl gene, encoding for the lysosomal enzyme glucocerebrosidase, are the most common genetic risk factor for Parkinson disease.

- A complex interaction exists between glucocerebrosidase and $\alpha$-synuclein.

- Gene therapy, small molecule chaperones and modulators targeting the glucocerebrosidase pathway, are promising therapies for Parkinson disease. 


\section{Declarations}

Funding: Nothing to report.

Conflicts of interest/Competing interests: AS is a Principle Investigator of the AIM-PD and MOVESPD studies.

Ethics approval: Not applicable.

Consent to participate: Not applicable.

Consent for publication: Not applicable.

Availability of data and material: Not applicable.

Code availability: Not applicable. 
Type of Manuscript: Leading Article (4119 words)

\section{Introduction}

"There appears to be sufficient reason for hoping that some remedial process may ere long be discovered, by which, at least, the progress of the disease may be stopped". After more than 200 years since James Parkinson wrote this prediction, we are now living in a time when the chance to slow the progression of Parkinson disease (PD) is probably more than just a hope. Novel treatments manipulating the pathway involving Glucocerebrosidase enzyme (GCase), encoded by the GBAl gene, offer potential to slow or even prevent PD in both individuals with and without $G B A 1$ mutations.

In this article, we provide an overview of the epidemiological burden of GBAl mutations in the PD population, review the mechanisms by which GCase dysfunction is thought to impact PD onset and progression, and conclude by examining the available treatments for PD that target the GCase pathway.

\section{GBA1 Mutations and Gaucher's disease}

GCase (also known as glucosylceramidase; EC 3.2.1.45) is a lysosomal enzyme which hydrolyses glucosylceramide (GlcCer) to ceramide and glucose. GCase is encoded by the GBAl gene located on chromosome 1q22. Homozygous or compound heterozygous mutations in the GBAl gene cause a marked decrease in GCase activity and accumulation of its substrates in the lysosomes, resulting in the autosomal recessive disorder Gaucher disease (GD) [1]. The incidence of GD is around 1/40,000 to $1 / 50,000$ births in the general population, and up to 1/800 births in the Ashkenazi Jewish population [1, 2]. GD is a systemic disorder that can present with a variety of visceral manifestations (hepatosplenomegaly, anaemia, thrombocytopenia) and neurological involvement. The degree of neurological involvement permits further categorization into three clinical subtypes: GD type 1 (OMIM 230800), the most common form, characterized by no neurological involvement; and GD type II (OMIM 230900) and type III (OMIM 231000), the neuronopathic variants [1]. More than 300 GBAI pathogenic variants have been associated with GD, including point mutations, insertions, deletions, splice-site mutations, and recombinant alleles [3], with the two most common being N370S and L444P [4]. The "mild" N370S mutation, which results in in-vitro residual enzyme activity of $32-38 \%$, is associated only with GD type I. The "severe" L444P mutation, with in-vitro residual activity of 13$24 \%$, is more often associated with GD types II and III [5, 6].

\section{GBA1 Mutations and Parkinson disease}

In the 1990s, some patients with GD [7] and asymptomatic GBAl carriers [8] were noted to have parkinsonian features. Neuropathologic findings subsequently confirmed classic PD pathology with aggregation of misfolded $\alpha$-synuclein into Lewy bodies (LBs) and neurites [9] in parkinsonian patients with GD [10, 11]. Heterozygous mutations in GBAl gene (OMIM 606463) are now considered the most significant genetic risk factor for PD, being present in 5\% to 15\% of Caucasian PD patients, $25 \%$ of Ashkenazi Jewish PD patients, and less than $1 \%$ of the general population [12]. More than 50 genetic studies have screened the GBAl gene in PD populations [13]: among the 130 variants of $G B A l$ which have been reported in association with $\mathrm{PD}, 11$ of them have been demonstrated to increase significantly the risk of PD worldwide, with odds ratios (ORs) ranging from 1.78 to 10.49 [12]. The common N370S and L444P mutations increase the risk of PD by approximately 4- and 8-to-12-fold, respectively [12]. The penetrance of GBAl variants is incomplete, variable across studies (approximately estimated between $10 \%$ and $30 \%$ in carriers), and age-specific $[14,15]$, with severe variants leading to a 3 - to 4fold higher risk and earlier disease onset compared to mild variants [16]. GBAl mutations have also been associated with increased risk of Dementia with Lewy Bodies (DLB), another form of 
synucleinopathy, with OR of 8.28 [17]. This association was recently confirmed by a genome-wide associated study [18], further supporting the relationship between GBAl pathway and synucleinopathies.

Notwithstanding the above, some caveats concerning the relationship between the GBAl pathway and PD need to be highlighted. First, PD has a similar incidence in homozygous and heterozygous carriers, though homozygous have a slightly earlier disease onset [19]. Second, common GBAl variants, such as E326K, predispose to PD by increasing the risk approximately 1.5-fold, but do not cause GD [12]. Third, GCase activity is reduced in brain tissue, cerebrospinal fluid and dried blood spots of PD patients carrying GBAl mutations as well as non-carriers [20-22]. Overall, this suggests that the connection between GCase and PD goes beyond the pathogenicity of mutations in the GBAl gene, and that additional mechanisms causing accumulation of $\alpha$-synuclein aggregates, such as age-related proteostasis dysfunction, might be involved in PD pathogenesis [23]. Nonetheless, unravelling the molecular mechanisms linking GCase with $\alpha$-synuclein is necessary to understand the pathogenesis of both sporadic and genetic forms of PD, and thus to develop specific targeted treatments.

\section{The Link Between GBA1 Mutations, GCase and $\alpha$-synuclein}

Three possible mechanisms linking GBAl mutations, GCase dysfunction and $\alpha$-synuclein pathology have been proposed.

\subsection{The GCase Gain-Of-Function and Endoplasmic Reticulum Stress Mechanism}

The first mechanism accounts for a gain-of-function role for GBAl mutations. The majority of GBAI mutations are missense mutations affecting the correct folding and maturation of the protein [4]. As such, misfolded GCase accumulates in the endoplasmic reticulum (ER) triggering an upregulation of ER stress response [24-26]. GCase is then translocated to the cytosol to be eliminated by the ubiquitin proteasome system, the so-called ER-associated degradation (ERAD); this process impedes mutant GCase from reaching the lysosome and impairs lysosomal GCase activity and function [27]. The presence of misfolded GCase, in turn, triggers the unfolded protein response (UPR) and interferes with the degradation of other proteins [28]. That said, how can misfolded GCase influence $\alpha$-synuclein levels? Several lines of evidence support a direct interaction between GCase and $\alpha$-synuclein [4]. The expression of mutant $G B A 1$ proteins promoted $\alpha$-synuclein accumulation in neuronal cells [29], as well as in vivo models of GD mice [29-31]. Similarly, intrastriatal injections of N370S mutant GBAl induced local increase of $\alpha$-synuclein secretion in mice overexpressing $\alpha$-synuclein [32]. The half-life of $\alpha$ synuclein in cells expressing mutant GCase was found to be significantly elevated in Drosophila [33] and mouse models [34], leading to its accumulation and aggregation. In humans, GCase has been found in 32-90\% of LBs of brain tissue samples from PD patients with GBAl mutations, and has been shown to co-localize with $\alpha$-synuclein [35]. It has also been reported that normal GCase can directly interact with the $\alpha$-synuclein $\mathrm{C}$-terminal residues in a $\mathrm{pH}$-dependent manner, that is within the lysosome [36]. Taken together, these findings support the strategy of regulating GCase trafficking as a potential treatment for PD.

\subsection{The GCase Loss-Of-Function/Haploinsufficiency and Substrate Accumulation Mechanism}

The second mechanism linking the GBAl pathway to PD proposes that the enzymatic deficiency resulting from loss-of-function or haploinsufficiency of GCase, leads to accumulation of substrates, thus affecting lipid homeostasis and $\alpha$-synuclein trafficking and clearance [4]. It has been demonstrated 
in both in vitro and in vivo models that the GCase inhibitor conduritol- $\beta$-epoxide $(\mathrm{C} \beta \mathrm{E})$ increases $\alpha$ synuclein levels [32, 37-39]. Even partial GCase inhibition caused by low doses of C $\beta E$ could promote marked microglia activation and enhance toxin-induced neurodegeneration in mice [40]. However, in primary neuron cultures, $\mathrm{C} \beta \mathrm{E}$ alone was not able to cause de novo $\alpha$-synuclein aggregation, but only to induce a dose-dependent increase when the pathological burden of $\alpha$-synuclein was initiated by preformed fibrils [41]. In addition to aggregation process, GCase depletion was also reported to be involved in cell-to-cell transmission of $\alpha$-synuclein aggregates [42].

Controversial data exist around the concept that GCase substrate GlcCer, or other sphingolipids accumulating in GD such as glucosylsphingosine (GlcSph), accumulate in the lysosome and trigger toxic $\alpha$-synuclein conformational change in GBAl-PD and GD-PD. Experiments conducted using induced pluripotent stem cells (iPSC) derived from GD patients and PD patients harbouring alphasynuclein gene (SNCA, OMIM 163890) triplication, showed that elevated GlcCer directly promoted the conversion of physiological $\alpha$-synuclein into insoluble forms and that the reduction of GlcCer was able to reverse the toxic conversion of $\alpha$-synuclein [43]. Furthermore, in human postmortem brain samples from GD patients, GlcCer levels controlled the formation of $\alpha$-synuclein oligomeric intermediates and induced polymerization of fibrils [44]. GlcSph has been shown to promote the formation of oligomeric $\alpha$-synuclein in young GD/PD mice brains [45]. In double mutant mice obtained by crossing $S N C A$ transgenic mice with $G B A 1$ heterozygous knockout mice, phosphorylated $\alpha$-synuclein was highly expressed in regions vulnerable to early-stage PD pathology, such as the olfactory bulb, and increased levels of GlcSph were reported [46]. In line with these data, significantly reduced GCase activity and increased GlcSph levels were detected in the substantia nigra and hippocampus of idiopathic PD patients during their sixth decade of life [47]. However, no accumulation of GlcCer and GlcSph was observed in the putamen and cerebellum samples from GBAl-PD patients [48]. Strategies to reduce substrate accumulation are currently being assessed in PD.

Ceramide homeostasis may also be implicated in PD pathogenesis. Data from postmortem brain studies of PD patients show that total ceramide levels including C18-ceramide are reduced in the anterior cingulate cortex, a region with significant PD pathology [49]. Decreased C18-ceramide species levels in GCase-deficient cells were shown to impair bafilomycin-A1-induced $\alpha$-synuclein secretion resulting in increased intracellular $\alpha$-synuclein accumulation, thus suggesting impaired secretory autophagy [50]. This secretory defect was rescued by exogenous C18-ceramide or chemical inhibition of lysosomal enzyme acid ceramidase (with carmofur) which resulted in decreased $\alpha$-synuclein in GBA1-PD patientderived dopaminergic neurons, increased ceramide levels and decreased GlcSph levels [50]. It is known that ceramide acts as a lipid second messenger to bind and activate cathepsin D (CTSD) [51], a lysosomal aspartic endo-protease which is involved in $\alpha$-synuclein degradation [52]. In GBAl mutant (WT/N370S) PD neurons, decreased levels of CTSD protein and its enzymatic activity were reported, together with monomeric $\alpha$-synuclein accumulation, implying that reduced CTSD occurred as a consequence of reduced mutant GCase activity and reduced ceramide levels [53]. Interestingly, GCase replacement therapy failed to lower $\alpha$-synuclein levels in the presence of CTSD inhibitor [53], suggesting that the ceramide-CTSD pathway can impact $\alpha$-synuclein levels and therefore might be considered as a target to reduce $\alpha$-synuclein pathology.

\subsection{The Positive Feedback Loop of GCase and $\alpha$-synuclein}

The pathological cascade of GCase and $\alpha$-synuclein alterations can rely on a third mechanism involving a bidirectional and reciprocal effect between GCase and $\alpha$-synuclein: increased $\alpha$-synuclein levels result in aberrant maturation and ER/Golgi apparatus trafficking of GCase, while GCase deficiency can promote $\alpha$-synuclein accumulation [44]. Two main studies support this hypothesis. In the first, overexpression of $\alpha$-synuclein in human primary cortical neurons altered the post-ER/ER GCase forms ratio by causing reduction of the former and accumulation of the latter, and decreased the GCase 
lysosomal activity [44]. On the other hand, GCase deficiency was shown to promote the formation of soluble oligomeric and insoluble $\alpha$-synuclein in vivo [44]. In the second study, human neuroblastoma SH-SY5Y cell lines over-expressing high levels of exogenous $\alpha$-synuclein (high $\alpha$-synuclein) were compared to cells expressing 10-fold lower levels of exogenous $\alpha$-synuclein: in high $\alpha$-synuclein cells, GCase activity and protein level were decreased by $70 \%$ and $87 \%$, respectively [20]. After endo-H digestion, high $\alpha$-synuclein cells showed an additional GCase band of lower molecular weight, indicating that a proportion of GCase was trapped prior to reaching the mid-Golgi apparatus [20]. Taken as a whole, these results suggest that therapeutic strategies aimed at restoring or improving GCase intracellular trafficking might be beneficial in the context of PD.

\subsection{Autophagy and GCase: Another Possible Link Towards Synucleinopathy}

Accumulating evidence suggests the prominent role of autophagy-lysosomal pathways (ALP) in PD pathogenesis [54]. Defects in the ALP system have been reported in human iPSC-derived dopamine neuron cultures from GD and PD patients carrying GBAl mutations, leading to increased release of extracellular $\alpha$-synuclein in these neurons [24, 55]. Similarly, adeno-associated virus (AAV)-mediated overexpression of N370S mutant GBAl in the mouse striatum resulted in increased local $\alpha$-synuclein secretion, and increased expression of ALP biomarkers [32]. In another report, GCase deficient cells showed autophagy lysosomal reformation dysfunction, which was accompanied by increased levels of total and phosphorylated monomeric $\alpha$-synuclein, oligomer deposition, and enhanced $\alpha$-synuclein release, indicating that defective lysosomal function may contribute to impaired ALP and $\alpha$-synuclein pathology [56]. Furthermore, rapamycin demonstrated beneficial effects in PD neuronal cell models, supporting that enhancing the ALP pathway may represent a useful therapeutic strategy in PD [57].

\section{From Mechanisms to Treatments: How We Can Target the GCase Pathway}

Due to the increased understanding of the pathogenetic mechanisms linking GCase dysfunction and $\alpha$ synuclein neuropathology, the manipulation of the GCase pathway has become an appealing therapeutic target in PD. Following the three main hypotheses explained above, most preclinical and clinical research has focused on A) enhancing GCase activity by replacing the mutant form of GCase, B) stabilizing the GCase mutant forms through molecular chaperones, and C) reducing the substrate accumulation by targeting the glycosphingolipid synthesis. Regardless which strategy is applied, the main purpose is to lower $\alpha$-synuclein levels and hence hopefully slow or halt the disease progression.

\subsection{Enhancing GCase Activity: Enzyme Replacement Therapy, Gene Therapy and other Modulators}

While enzyme replacement therapy has remained one of the standard treatments for GD since 1991 [58], recombinant GCase imiglucerase does not cross the blood-brain barrier (BBB) and therefore has no effect on the CNS [59].

Alternative strategies to restore physiological GCase activity in the brain include $G B A 1$ overexpression by AAV. Viral delivery of wild-type GBAl showed a trend to reduce $\alpha$-synuclein abnormalities and memory deficits in a GD mouse model [60]. Similar beneficial effects were replicated in mouse models that did not carry any GBAl mutations, indicating that enhancing GCase activity by gene therapy could prevent synucleinopathy regardless of GBAl mutational status [30, 61-63]. Moreover, ectopic expression of wild-type $G B A l$ was reported to reverse the effects of $G B A l$ gene deletion on the propagation and cell-to-cell transmission of $\alpha$-synuclein aggregates [42], suggesting its ability to impact $\alpha$-synuclein pathology at different steps. A multicenter, randomized, double-blind, sham procedure- 
controlled, phase $1 / 2$ a clinical trial has recently started recruiting patients with moderate to severe PD with at least 1 pathogenic GBAl mutation, to evaluate the safety of intra-cisternal PR001A administration (single-dose gene therapy using an AAV9 viral vector), with two escalating dose cohorts (PROPEL study, NCT04127578). A phase 1/2 study testing PR001A in neuronopathic GD is also expected to begin soon.

Regulators of gene expression may also be appealing therapeutic strategies. In this context, a very important role is played by microRNAs (miRNAs), a class of small non-coding RNAs, which can mediate gene silencing post-transcriptionally by mRNA degradation and/or repression of translation [64]. In human PD brains, miR-127-5p, which has been shown to reduce GCase activity, and miR-16$5 p$, which has been shown to enhance GCase protein levels [65], were found to be downregulated and upregulated, respectively [66]. An additional regulatory circuit possibly associated with PD, could involve the GBAl pseudogene through its ability to act as a competing-endogenous RNA (ceRNA) titrating miR-22-3p ("miRNA sponging") and thus up-regulating the levels of GBAl mRNA [67].

Next to recombinant GCase or gene therapy, the activity of wild-type GCase can be enhanced using small molecular modulators of GCase. The rational of using such molecules is that individuals carrying GBA1 mutations such as $84 \mathrm{GG}$, do not express the mutant protein [68], and wild-type GCase enzyme activity was reported to be reduced in iPSC-derived dopaminergic neurons from patients with genetic or idiopathic PD who did not harbour GBAl mutations [69, 70]. For instance, the GCase modulator S181 was shown to ameliorate lysosomal dysfunction and $\alpha$-synuclein accumulation in both $G B A 1$ and non-GBAl PD iPSC-derived dopaminergic neurons [68]. In a GBAl heterozygous mouse model, S-181 was able to penetrate the CNS, activate the wild-type GCase and reduce $\alpha$-synuclein [68]. Similarly, small molecular chaperones such as ambroxol were reported to increase GBAI mRNA and protein levels and enzymatic activity in several cell and animal models (see below) [26, 71-73].

In conclusion, the development of targeted therapies that are based on the genetic background of PD is likely to have an important impact on the disease course, and future studies are needed to test the efficacy of GBAl-overexpressing therapies and/or develop the most effective wild-type GCase modulators for testing in human clinical trials.

\subsection{Substrate Reduction Therapy}

Through the inhibition of glycosphingolipid synthesis and the restoration of a more physiological GCase substrate ratio, substrate reduction therapies (eligustat and miglustat) represent a valid alternative to control visceral symptoms in patients with GD type I. Miglustat has been shown to reduce glycosphingolipid accumulation and $\alpha$-synuclein preformed fibril toxicity in human dopaminergic neuronal cells [74]. However, the effectiveness of miglustat or eliglustat is limited in neuronopathic GD and PD due to their inability to pass the BBB [59]. Venglustat (GZ/SAR402671) is an oral GlcCer synthase inhibitor, which can cross the BBB. A multicenter, randomized, double-blind, placebocontrolled phase 2 study is currently ongoing to assess the safety, drugs dynamics and efficacy of venglustat in GBAl carriers with early-stage PD (MOVES-PD study, NCT02906020). Another CNSpenetrant GlcCer synthase inhibitor, GZ667161, has been reported to improve $\alpha$-synuclein processing and behavioural outcomes in both $\alpha$-synuclein overexpressing mice and mice carrying homozygous GBAl mutations [75], further indicating a potential for clinical applications of GlcCer synthase inhibitors in PD patients.

\subsection{Stabilizing GCase Mutant: Small Molecular Chaperones}


Based on the observation that misfolded GCase is sequestered within the ER, small chemical chaperones can act as cofactors that stabilize and refold misfolded protein, in turn upregulating postER trafficking of mutant GCase to the lysosome [76]. As they are small enough to cross the BBB, they represent a promising therapeutic option in PD [77]. Molecular chaperones can be categorized into two groups. The first one includes inhibitory chaperones, that can directly bind to the active site of the GCase protein, antagonizing the binding of the enzyme substrates and hence reducing the enzymatic activity [76]. To date, the majority of GCase chaperones discovered are inhibitory. However, if the affinity of the chaperone for the substrate is too high, the active site will remain bound to the chaperone: as a result, the chaperone will inhibit rather than increase GCase activity within the lysosome [76]. Within this category, the compound AT2101 (afegostat-tartrate, or isofagomine) has shown promising results in in vitro and in vivo studies [78-80], however clinical trials testing this compound in patients with GD were unsuccessful, possibly due to the high-binding affinity to the active site up to $\mathrm{pH} 4$ [76]. The second group of compounds includes non-inhibitory chaperones, that can bind the enzyme out of the active site, but yet are still able to modulate the folding sufficiently to restore or partially restore posttranslational folding [81]. Recently, a number of non-inhibitory chaperones of GCase have been identified through high-throughput screening systems using the spleen-lysate and patient's fibroblast $[82,83]$. It was shown that the lead compound NCGC00188758 of a class of noninhibitory chaperone molecules potently activated and promoted the translocation of mutant GCase into lysosomes [84]. Some of these GCase modulators, such as NCGC00188758 [85] or NCGC607 [86], were applied to stable cell lines and multiple iPSC neuronal lines derived from PD patients harbouring distinct mutations in SNCA or GBA1, as well as idiopathic PD. The results showed that both NCGC607 and NCGC00188758 could enhance GCase lysosomal activity, reduce $\alpha$-synuclein accumulation and reverse neurotoxicity $[85,86]$.

Among the class of small chaperones, ambroxol is one of the most promising candidates as a diseasemodifying treatment in PD. Used as an expectorant for over 30 years within the dose range of 75-100 $\mathrm{mg}$ /day for adults, ambroxol is characterized by good lipophilicity and low polar surface area, thus predicting good CNS penetration [87]. It also has an excellent safety record with its principal adverse effects being gastrointestinal disturbance and a small risk of anaphylaxis [76]. In 2009, a screen of a FDA-approved drug library identified ambroxol as a pH-dependent mixed inhibitor of GCase [88], and more than 10 years after, it is currently in clinical trials in PD patients [87, 89]. Ambroxol can bind both active and non-active site residues of GCase protein [88], thus enhancing the folding of mutant GCase in the ER and facilitating the shuttling to the lysosome [90]. Within the lysosome, it is then eluted, allowing normal catalysis to resume and restoring lysosomal function [89]. A number of in vitro and in vivo studies have reported that ambroxol can increase GCase activity and also reduce $\alpha$-synuclein levels $[26,71-73,90,91]$. The modulation of $\alpha$-synuclein levels can rely on different mechanisms, such as by 1) upregulating GCase expression through the transcription factor EB pathway and thus stimulating lysosomal exocytosis [71, 92], and/or 2) correcting the GCase posttranslational folding and mitigating the UPR [90]. A single-centre open-label noncontrolled clinical trial of oral ambroxol therapy (escalating dose to $1.26 \mathrm{~g}$ per day) was recently conducted in 17 patients with moderate PD with and without GBA1 mutations [89]. The study confirmed that ambroxol is able to penetrate CSF and is well tolerated in patients with PD (even at a 10-times higher dose and longer duration of administration than specified in its license). A significant increase in CSF $\alpha$-synuclein concentration and GCase protein was observed, together with a significant improvement in motor symptoms severity [89]. Another phase II, single-center, double-blind, randomized placebo-controlled trial (NCT02914366) involving 75 individuals with mild to moderate PD-Dementia, randomly assigned to high-dose (1050 mg/day), lowdose $(525 \mathrm{mg} /$ day $)$, or placebo treatment arms, is currently on-going. Primary outcome measures will be any changes in the cognitive scales [87].

Next to intrinsic chaperones, extrinsic chaperones are proteins that serve to stabilize and refold proteins during periods of extreme stress that disrupt proteostasis, such as heat shock [77]. Within this group, members of the heat shock protein 70 (HSP70) family have been shown to be essential for proper 
lysosomal and GCase function [93]. Arimoclomol, a small molecule amplifier of HSP70, was shown to enhance the folding, maturation, activity, and cellular localization of mutated GCase in primary fibroblasts and neuronal-like cells from GD patients [93]. This compound is currently evaluated in a clinical trial for GD type I and III (NCT03746587), but it has not yet been studied in PD.

\subsection{Alternative Approaches to Manipulate the GCase Pathway}

It is well-known that GCase is transported from the ER by the GCase transporter lysosomal integral membrane protein-2 (LIMP-2), which is encoded by the scavenger receptor class B member 2 (SCARB2) gene (OMIM 602257) [94]. Genetic variations in the SCARB2 gene have been associated with an increased risk of developing PD [95], so manipulation of LIMP-2 expression might represent a valid strategy for PD treatment. A direct relationship between LIMP-2 expression and $\alpha$-synuclein accumulation has been demonstrated in LIMP-2 ${ }^{-/}$mouse models where LIMP-2 depletion resulted in accumulation of soluble and insoluble oligomeric $\alpha$-synuclein species in brain, likely due to lysosomal deficiency of GCase and subsequent accumulation of substrates [96]. In murine neuroblastoma cell lines, heterologous expression of wild-type LIMP-2 led to a significant reduction in $\alpha$-synuclein protein [96]. Structural models of the interaction site between LIMP-2 and GCase have been proposed, paving the way to the design of small molecules targeting the LIMP-2/GCase complex [97].

Recently, the leucine rich repeat kinase 2 (LRRK2) gene (OMIM 609007) has been proposed as a negative regulator of lysosomal GCase activity [98]. In this report, LRKK2 mutations resulted in reduced GCase activity in human dopaminergic neurons, and the inhibition of $L R R K 2$ kinase activity restored GCase activity in neurons carrying either $L R R K 2$ or GBAl mutations, and rescued neurons from PD phenotype [98]. Therefore, due to its influence on the GCase pathway, LRKK2 inhibition may be beneficial for PD patients, and the relationship between the two proteins deserves to be further investigated.

Finally, the GCase pathway can be manipulated by the modulation of misfolded GCase degradation through small molecule compounds such as histone deacetylase inhibitors (HDACis). HDACis cause hyperacetylation of chaperones such as Hsp90, limiting their affinity to misfolded GCase protein and preventing the subsequent UPR-related degradation, thus increasing the quantity of GCase and overall catalytic activity of GCase in fibroblasts from GD patients [99, 100].

Taken together, these data suggest that future studies might evaluate the effects of LIMP-2, LRKK2 inhibition and HDACis in slowing the pathological progression of $\alpha$-synuclein in PD models.

\section{Conclusions}

The association between mutations of the GBAl gene and PD is one the most interesting and promising discoveries related to PD pathogenesis. The available evidence from in vitro and in vivo studies indeed indicates that GCase activity and $\alpha$-synuclein levels have a reciprocal relationship. Although which of the molecular mechanisms involved in the GCase pathway prevails over the others, or how they coexist, in determining $\alpha$-synuclein pathology remains unclear, ongoing translation studies have been focused on designing molecules that can target the GCase pathway and reduce $\alpha$-synuclein accumulation. Clinical trials evaluating some of these compounds are already underway in PD patients, with the purpose of demonstrating their disease-modifying potential, thus making James Parkinson's hope a forthcoming reality. 


\section{References}

1. Grabowski GA. Phenotype, diagnosis, and treatment of Gaucher's disease. Lancet. 2008 Oct 4;372(9645):1263-71.

2. Stirnemann J, Vigan M, Hamroun D, Heraoui D, Rossi-Semerano L, Berger MG, et al. The French Gaucher's disease registry: clinical characteristics, complications and treatment of 562 patients. Orphanet journal of rare diseases. 2012 Oct 9;7:77.

3. Hruska KS, LaMarca ME, Scott CR, Sidransky E. Gaucher disease: mutation and polymorphism spectrum in the glucocerebrosidase gene (GBA). Human mutation. 2008 May;29(5):567-83.

4. Sidransky E, Lopez G. The link between the GBA gene and parkinsonism. The Lancet Neurology. 2012 Nov;11(11):986-98.

5. Alfonso P, Rodriguez-Rey JC, Ganan A, Perez-Calvo JI, Giralt M, Giraldo P, et al. Expression and functional characterization of mutated glucocerebrosidase alleles causing Gaucher disease in Spanish patients. Blood cells, molecules \& diseases. 2004 Jan-Feb;32(1):218-25.

6. Malini E, Grossi S, Deganuto M, Rosano C, Parini R, Dominisini S, et al. Functional analysis of 11 novel GBA alleles. European journal of human genetics : EJHG. 2014 Apr;22(4):511-6.

7. Neudorfer O, Giladi N, Elstein D, Abrahamov A, Turezkite T, Aghai E, et al. Occurrence of Parkinson's syndrome in type I Gaucher disease. QJM : monthly journal of the Association of Physicians. 1996 Sep;89(9):691-4.

8. Goker-Alpan O, Schiffmann R, LaMarca ME, Nussbaum RL, Mclnerney-Leo A, Sidransky E. Parkinsonism among Gaucher disease carriers. Journal of medical genetics. 2004 Dec;41(12):937-40.

9. Spillantini MG, Schmidt ML, Lee VM, Trojanowski JQ, Jakes R, Goedert M. Alpha-synuclein in Lewy bodies. Nature. 1997 Aug 28;388(6645):839-40.

10. Tayebi N, Walker J, Stubblefield B, Orvisky E, LaMarca ME, Wong K, et al. Gaucher disease with parkinsonian manifestations: does glucocerebrosidase deficiency contribute to a vulnerability to parkinsonism? Molecular genetics and metabolism. 2003 Jun;79(2):104-9.

11. Wong K, Sidransky E, Verma A, Mixon T, Sandberg GD, Wakefield LK, et al. Neuropathology provides clues to the pathophysiology of Gaucher disease. Molecular genetics and metabolism. 2004 Jul;82(3):192-207.

12. Zhang Y, Shu L, Sun Q, Zhou X, Pan H, Guo J, et al. Integrated Genetic Analysis of Racial Differences of Common GBA Variants in Parkinson's Disease: A Meta-Analysis. Frontiers in molecular neuroscience. 2018;11:43.

13. Riboldi GM, Di Fonzo AB. GBA, Gaucher Disease, and Parkinson's Disease: From Genetic to Clinic to New Therapeutic Approaches. Cells. 2019 Apr 19;8(4).

14. Anheim M, Elbaz A, Lesage S, Durr A, Condroyer C, Viallet F, et al. Penetrance of Parkinson disease in glucocerebrosidase gene mutation carriers. Neurology. 2012 Feb 7;78(6):417-20.

15. Rana HQ, Balwani M, Bier L, Alcalay RN. Age-specific Parkinson disease risk in GBA mutation carriers: information for genetic counseling. Genetics in medicine : official journal of the American College of Medical Genetics. 2013 Feb;15(2):146-9.

16. Gan-Or Z, Amshalom I, Kilarski LL, Bar-Shira A, Gana-Weisz M, Mirelman A, et al. Differential effects of severe vs mild GBA mutations on Parkinson disease. Neurology. 2015 Mar 3;84(9):880-7.

17. Nalls MA, Duran R, Lopez G, Kurzawa-Akanbi M, McKeith IG, Chinnery PF, et al. A multicenter study of glucocerebrosidase mutations in dementia with Lewy bodies. JAMA neurology. 2013 Jun;70(6):727-35.

18. Guerreiro R, Ross OA, Kun-Rodrigues C, Hernandez DG, Orme T, Eicher JD, et al. Investigating the genetic architecture of dementia with Lewy bodies: a two-stage genome-wide association study. The Lancet Neurology. 2018 Jan;17(1):64-74.

19. Alcalay RN, Dinur T, Quinn T, Sakanaka K, Levy O, Waters C, et al. Comparison of Parkinson risk in Ashkenazi Jewish patients with Gaucher disease and GBA heterozygotes. JAMA neurology. 2014 Jun;71(6):752-7. 
20. Gegg ME, Burke D, Heales SJ, Cooper JM, Hardy J, Wood NW, et al. Glucocerebrosidase deficiency in substantia nigra of parkinson disease brains. Annals of neurology. 2012 Sep;72(3):45563.

21. Alcalay RN, Levy OA, Waters CC, Fahn S, Ford B, Kuo SH, et al. Glucocerebrosidase activity in Parkinson's disease with and without GBA mutations. Brain : a journal of neurology. $2015 \mathrm{Sep} ; 138(\mathrm{Pt}$ 9):2648-58.

22. Parnetti L, Paciotti S, Eusebi P, Dardis A, Zampieri S, Chiasserini D, et al. Cerebrospinal fluid beta-glucocerebrosidase activity is reduced in parkinson's disease patients. Movement disorders : official journal of the Movement Disorder Society. 2017 Oct;32(10):1423-31.

23. Hipp MS, Kasturi P, Hartl FU. The proteostasis network and its decline in ageing. Nature reviews Molecular cell biology. 2019 Jul;20(7):421-35.

24. Fernandes HJ, Hartfield EM, Christian HC, Emmanoulidou E, Zheng $\mathrm{Y}$, Booth $\mathrm{H}$, et al. ER Stress and Autophagic Perturbations Lead to Elevated Extracellular alpha-Synuclein in GBA-N370S Parkinson's iPSC-Derived Dopamine Neurons. Stem cell reports. 2016 Mar 8;6(3):342-56.

25. Garcia-Sanz P, Orgaz L, Bueno-Gil G, Espadas I, Rodriguez-Traver E, Kulisevsky J, et al. N370SGBA1 mutation causes lysosomal cholesterol accumulation in Parkinson's disease. Movement disorders : official journal of the Movement Disorder Society. 2017 Oct;32(10):1409-22.

26. McNeill A, Magalhaes J, Shen C, Chau KY, Hughes D, Mehta A, et al. Ambroxol improves lysosomal biochemistry in glucocerebrosidase mutation-linked Parkinson disease cells. Brain : a journal of neurology. 2014 May;137(Pt 5):1481-95.

27. Bendikov-Bar I, Ron I, Filocamo M, Horowitz M. Characterization of the ERAD process of the L444P mutant glucocerebrosidase variant. Blood cells, molecules \& diseases. 2011 Jan 15;46(1):4-10. 28. Maor G, Rencus-Lazar S, Filocamo M, Steller H, Segal D, Horowitz M. Unfolded protein response in Gaucher disease: from human to Drosophila. Orphanet journal of rare diseases. 2013 Sep 11;8:140.

29. Cullen V, Sardi SP, Ng J, Xu YH, Sun Y, Tomlinson JJ, et al. Acid beta-glucosidase mutants linked to Gaucher disease, Parkinson disease, and Lewy body dementia alter alpha-synuclein processing. Annals of neurology. 2011 Jun;69(6):940-53.

30. Sardi SP, Clarke J, Viel C, Chan M, Tamsett TJ, Treleaven CM, et al. Augmenting CNS glucocerebrosidase activity as a therapeutic strategy for parkinsonism and other Gaucher-related synucleinopathies. Proceedings of the National Academy of Sciences of the United States of America. 2013 Feb 26;110(9):3537-42.

31. Xu YH, Xu K, Sun Y, Liou B, Quinn B, Li RH, et al. Multiple pathogenic proteins implicated in neuronopathic Gaucher disease mice. Human molecular genetics. 2014 Aug 1;23(15):3943-57.

32. Papadopoulos VE, Nikolopoulou G, Antoniadou I, Karachaliou A, Arianoglou G, Emmanouilidou $E$, et al. Modulation of beta-glucocerebrosidase increases alpha-synuclein secretion and exosome release in mouse models of Parkinson's disease. Human molecular genetics. 2018 May 15;27(10):1696-710.

33. Maor G, Rapaport D, Horowitz M. The effect of mutant GBA1 on accumulation and aggregation of alpha-synuclein. Human molecular genetics. 2019 Jun 1;28(11):1768-81.

34. Fishbein I, Kuo YM, Giasson BI, Nussbaum RL. Augmentation of phenotype in a transgenic Parkinson mouse heterozygous for a Gaucher mutation. Brain : a journal of neurology. 2014 Dec;137(Pt 12):3235-47.

35. Goker-Alpan O, Stubblefield BK, Giasson BI, Sidransky E. Glucocerebrosidase is present in alpha-synuclein inclusions in Lewy body disorders. Acta neuropathologica. 2010 Nov;120(5):641-9. 36. Yap TL, Gruschus JM, Velayati A, Westbroek W, Goldin E, Moaven N, et al. Alpha-synuclein interacts with Glucocerebrosidase providing a molecular link between Parkinson and Gaucher diseases. The Journal of biological chemistry. 2011 Aug 12;286(32):28080-8.

37. Cleeter MW, Chau KY, Gluck C, Mehta A, Hughes DA, Duchen M, et al. Glucocerebrosidase inhibition causes mitochondrial dysfunction and free radical damage. Neurochemistry international. 2013 Jan;62(1):1-7. 
38. Manning-Bog AB, Schule B, Langston JW. Alpha-synuclein-glucocerebrosidase interactions in pharmacological Gaucher models: a biological link between Gaucher disease and parkinsonism. Neurotoxicology. 2009 Nov;30(6):1127-32.

39. Rocha EM, Smith GA, Park E, Cao H, Graham AR, Brown E, et al. Sustained Systemic Glucocerebrosidase Inhibition Induces Brain alpha-Synuclein Aggregation, Microglia and Complement C1q Activation in Mice. Antioxidants \& redox signaling. 2015 Aug 20;23(6):550-64. 40. Mus L, Siani F, Giuliano C, Ghezzi C, Cerri S, Blandini F. Development and biochemical characterization of a mouse model of Parkinson's disease bearing defective glucocerebrosidase activity. Neurobiology of disease. 2019 Apr;124:289-96.

41. Henderson MX, Sedor S, McGeary I, Cornblath EJ, Peng C, Riddle DM, et al. Glucocerebrosidase Activity Modulates Neuronal Susceptibility to Pathological alpha-Synuclein Insult. Neuron. 2020 Mar 4;105(5):822-36 e7.

42. Bae EJ, Yang NY, Song M, Lee CS, Lee JS, Jung BC, et al. Glucocerebrosidase depletion enhances cell-to-cell transmission of alpha-synuclein. Nature communications. 2014 Aug 26;5:4755. 43. Zunke F, Moise AC, Belur NR, Gelyana E, Stojkovska I, Dzaferbegovic H, et al. Reversible Conformational Conversion of alpha-Synuclein into Toxic Assemblies by Glucosylceramide. Neuron. 2018 Jan 3;97(1):92-107 e10.

44. Mazzulli JR, Xu YH, Sun Y, Knight AL, McLean PJ, Caldwell GA, et al. Gaucher disease glucocerebrosidase and alpha-synuclein form a bidirectional pathogenic loop in synucleinopathies. Cell. 2011 Jul 8;146(1):37-52.

45. Taguchi YV, Liu J, Ruan J, Pacheco J, Zhang X, Abbasi J, et al. Glucosylsphingosine Promotes alpha-Synuclein Pathology in Mutant GBA-Associated Parkinson's Disease. The Journal of neuroscience : the official journal of the Society for Neuroscience. 2017 Oct 4;37(40):9617-31.

46. Ikuno M, Yamakado H, Akiyama H, Parajuli LK, Taguchi K, Hara J, et al. GBA haploinsufficiency accelerates alpha-synuclein pathology with altered lipid metabolism in a prodromal model of Parkinson's disease. Human molecular genetics. 2019 Jun 1;28(11):1894-904. 47. Rocha EM, Smith GA, Park E, Cao H, Brown E, Hallett P, et al. Progressive decline of glucocerebrosidase in aging and Parkinson's disease. Annals of clinical and translational neurology. 2015 Apr;2(4):433-8.

48. Gegg ME, Sweet L, Wang BH, Shihabuddin LS, Sardi SP, Schapira AH. No evidence for substrate accumulation in Parkinson brains with GBA mutations. Movement disorders : official journal of the Movement Disorder Society. 2015 Jul;30(8):1085-9.

49. Abbott SK, Li H, Munoz SS, Knoch B, Batterham M, Murphy KE, et al. Altered ceramide acyl chain length and ceramide synthase gene expression in Parkinson's disease. Movement disorders : official journal of the Movement Disorder Society. 2014 Apr;29(4):518-26.

50. Kim MJ, Jeon S, Burbulla LF, Krainc D. Acid ceramidase inhibition ameliorates alpha-synuclein accumulation upon loss of GBA1 function. Human molecular genetics. 2018 Jun 1;27(11):1972-88.

51. Heinrich M, Wickel M, Winoto-Morbach S, Schneider-Brachert W, Weber T, Brunner J, et al. Ceramide as an activator lipid of cathepsin D. Advances in experimental medicine and biology. 2000;477:305-15.

52. Sevlever $D$, Jiang $P$, Yen $\mathrm{SH}$. Cathepsin $\mathrm{D}$ is the main lysosomal enzyme involved in the degradation of alpha-synuclein and generation of its carboxy-terminally truncated species. Biochemistry. 2008 Sep 9;47(36):9678-87.

53. Yang SY, Gegg M, Chau D, Schapira A. Glucocerebrosidase activity, cathepsin D and monomeric alpha-synuclein interactions in a stem cell derived neuronal model of a PD associated GBA1 mutation. Neurobiology of disease. 2020 Feb;134:104620.

54. Dehay B, Martinez-Vicente M, Caldwell GA, Caldwell KA, Yue Z, Cookson MR, et al. Lysosomal impairment in Parkinson's disease. Movement disorders : official journal of the Movement Disorder Society. 2013 Jun;28(6):725-32. 
55. Schondorf DC, Aureli M, McAllister FE, Hindley CJ, Mayer F, Schmid B, et al. iPSC-derived neurons from GBA1-associated Parkinson's disease patients show autophagic defects and impaired calcium homeostasis. Nature communications. 2014 Jun 6;5:4028.

56. Magalhaes J, Gegg ME, Migdalska-Richards A, Doherty MK, Whitfield PD, Schapira AH. Autophagic lysosome reformation dysfunction in glucocerebrosidase deficient cells: relevance to Parkinson disease. Human molecular genetics. 2016 Aug 15;25(16):3432-45.

57. Pan T, Rawal P, Wu Y, Xie W, Jankovic J, Le W. Rapamycin protects against rotenone-induced apoptosis through autophagy induction. Neuroscience. 2009 Dec 1;164(2):541-51.

58. Barton NW, Brady RO, Dambrosia JM, Di Bisceglie AM, Doppelt SH, Hill SC, et al.

Replacement therapy for inherited enzyme deficiency--macrophage-targeted glucocerebrosidase for Gaucher's disease. The New England journal of medicine. 1991 May 23;324(21):1464-70.

59. Stojkovska I, Krainc D, Mazzulli JR. Molecular mechanisms of alpha-synuclein and GBA1 in Parkinson's disease. Cell and tissue research. $2018 \mathrm{Jul} ; 373(1): 51-60$.

60. Sardi SP, Clarke J, Kinnecom C, Tamsett TJ, Li L, Stanek LM, et al. CNS expression of glucocerebrosidase corrects alpha-synuclein pathology and memory in a mouse model of Gaucherrelated synucleinopathy. Proceedings of the National Academy of Sciences of the United States of America. 2011 Jul 19;108(29):12101-6.

61. Rocha EM, Smith GA, Park E, Cao H, Brown E, Hayes MA, et al. Glucocerebrosidase gene therapy prevents alpha-synucleinopathy of midbrain dopamine neurons. Neurobiology of disease. 2015 Oct;82:495-503.

62. Rockenstein E, Clarke J, Viel C, Panarello N, Treleaven CM, Kim C, et al. Glucocerebrosidase modulates cognitive and motor activities in murine models of Parkinson's disease. Human molecular genetics. 2016 Jul 1;25(13):2645-60.

63. Morabito G, Giannelli SG, Ordazzo G, Bido S, Castoldi V, Indrigo M, et al. AAV-PHP.BMediated Global-Scale Expression in the Mouse Nervous System Enables GBA1 Gene Therapy for Wide Protection from Synucleinopathy. Molecular therapy : the journal of the American Society of Gene Therapy. 2017 Dec 6;25(12):2727-42.

64. Chang TC, Mendell JT. microRNAs in vertebrate physiology and human disease. Annual review of genomics and human genetics. 2007;8:215-39.

65. Siebert M, Westbroek W, Chen YC, Moaven N, Li Y, Velayati A, et al. Identification of miRNAs that modulate glucocerebrosidase activity in Gaucher disease cells. RNA biology. 2014;11(10):1291300.

66. Hoss AG, Labadorf A, Beach TG, Latourelle JC, Myers RH. microRNA Profiles in Parkinson's Disease Prefrontal Cortex. Frontiers in aging neuroscience. 2016;8:36.

67. Straniero L, Rimoldi V, Samarani M, Goldwurm S, Di Fonzo A, Kruger R, et al. The GBAP1 pseudogene acts as a ceRNA for the glucocerebrosidase gene GBA by sponging miR-22-3p. Scientific reports. 2017 Oct 5;7(1):12702.

68. Burbulla LF, Jeon S, Zheng J, Song P, Silverman RB, Krainc D. A modulator of wild-type glucocerebrosidase improves pathogenic phenotypes in dopaminergic neuronal models of Parkinson's disease. Science translational medicine. 2019 Oct 16;11(514).

69. Burbulla LF, Song P, Mazzulli JR, Zampese E, Wong YC, Jeon S, et al. Dopamine oxidation mediates mitochondrial and lysosomal dysfunction in Parkinson's disease. Science. 2017 Sep 22;357(6357):1255-61.

70. Nguyen M, Krainc D. LRRK2 phosphorylation of auxilin mediates synaptic defects in dopaminergic neurons from patients with Parkinson's disease. Proceedings of the National Academy of Sciences of the United States of America. 2018 May 22;115(21):5576-81.

71. Magalhaes J, Gegg ME, Migdalska-Richards A, Schapira AH. Effects of ambroxol on the autophagy-lysosome pathway and mitochondria in primary cortical neurons. Scientific reports. 2018 Jan 23;8(1):1385.

72. Migdalska-Richards A, Daly L, Bezard E, Schapira AH. Ambroxol effects in glucocerebrosidase and alpha-synuclein transgenic mice. Annals of neurology. 2016 Nov;80(5):766-75. 
73. Migdalska-Richards A, Ko WKD, Li Q, Bezard E, Schapira AHV. Oral ambroxol increases brain glucocerebrosidase activity in a nonhuman primate. Synapse. $2017 \mathrm{Jul} ; 71(7)$.

74. Kim S, Yun SP, Lee S, Umanah GE, Bandaru VVR, Yin X, et al. GBA1 deficiency negatively affects physiological alpha-synuclein tetramers and related multimers. Proceedings of the National Academy of Sciences of the United States of America. 2018 Jan 23;115(4):798-803.

75. Sardi SP, Viel C, Clarke J, Treleaven CM, Richards AM, Park H, et al. Glucosylceramide synthase inhibition alleviates aberrations in synucleinopathy models. Proceedings of the National Academy of Sciences of the United States of America. 2017 Mar 7;114(10):2699-704.

76. Blandini F, Cilia R, Cerri S, Pezzoli G, Schapira AHV, Mullin S, et al. Glucocerebrosidase mutations and synucleinopathies: Toward a model of precision medicine. Movement disorders : official journal of the Movement Disorder Society. 2019 Jan;34(1):9-21.

77. Do J, McKinney C, Sharma P, Sidransky E. Glucocerebrosidase and its relevance to Parkinson disease. Molecular neurodegeneration. 2019 Aug 29;14(1):36.

78. Khanna R, Benjamin ER, Pellegrino L, Schilling A, Rigat BA, Soska R, et al. The pharmacological chaperone isofagomine increases the activity of the Gaucher disease L444P mutant form of beta-glucosidase. The FEBS journal. 2010 Apr;277(7):1618-38.

79. Richter F, Fleming SM, Watson M, Lemesre V, Pellegrino L, Ranes B, et al. A GCase chaperone improves motor function in a mouse model of synucleinopathy. Neurotherapeutics : the journal of the American Society for Experimental NeuroTherapeutics. 2014 Oct;11(4):840-56.

80. Sun Y, Liou B, Xu YH, Quinn B, Zhang W, Hamler R, et al. Ex vivo and in vivo effects of isofagomine on acid beta-glucosidase variants and substrate levels in Gaucher disease. The Journal of biological chemistry. 2012 Feb 3;287(6):4275-87.

81. Jung O, Patnaik S, Marugan J, Sidransky E, Westbroek W. Progress and potential of noninhibitory small molecule chaperones for the treatment of Gaucher disease and its implications for Parkinson disease. Expert review of proteomics. 2016 May;13(5):471-9.

82. Goldin E, Zheng W, Motabar O, Southall N, Choi JH, Marugan J, et al. High throughput screening for small molecule therapy for Gaucher disease using patient tissue as the source of mutant glucocerebrosidase. PloS one. 2012;7(1):e29861.

83. Patnaik S, Zheng W, Choi JH, Motabar O, Southall N, Westbroek W, et al. Discovery, structure-activity relationship, and biological evaluation of noninhibitory small molecule chaperones of glucocerebrosidase. Journal of medicinal chemistry. 2012 Jun 28;55(12):5734-48.

84. Aflaki E, Stubblefield BK, Maniwang E, Lopez G, Moaven N, Goldin E, et al. Macrophage models of Gaucher disease for evaluating disease pathogenesis and candidate drugs. Science translational medicine. 2014 Jun 11;6(240):240ra73.

85. Mazzulli JR, Zunke F, Tsunemi T, Toker NJ, Jeon S, Burbulla LF, et al. Activation of betaGlucocerebrosidase Reduces Pathological alpha-Synuclein and Restores Lysosomal Function in Parkinson's Patient Midbrain Neurons. The Journal of neuroscience : the official journal of the Society for Neuroscience. 2016 Jul 20;36(29):7693-706.

86. Aflaki E, Borger DK, Moaven N, Stubblefield BK, Rogers SA, Patnaik S, et al. A New Glucocerebrosidase Chaperone Reduces alpha-Synuclein and Glycolipid Levels in iPSC-Derived Dopaminergic Neurons from Patients with Gaucher Disease and Parkinsonism. The Journal of neuroscience : the official journal of the Society for Neuroscience. $2016 \mathrm{Jul}$ 13;36(28):7441-52. 87. Silveira CRA, MacKinley J, Coleman K, Li Z, Finger E, Bartha R, et al. Ambroxol as a novel disease-modifying treatment for Parkinson's disease dementia: protocol for a single-centre, randomized, double-blind, placebo-controlled trial. BMC neurology. 2019 Feb 9;19(1):20.

88. Maegawa GH, Tropak MB, Buttner JD, Rigat BA, Fuller M, Pandit D, et al. Identification and characterization of ambroxol as an enzyme enhancement agent for Gaucher disease. The Journal of biological chemistry. 2009 Aug 28;284(35):23502-16.

89. Mullin S, Smith L, Lee K, D'Souza G, Woodgate P, Elflein J, et al. Ambroxol for the Treatment of Patients With Parkinson Disease With and Without Glucocerebrosidase Gene Mutations: A Nonrandomized, Noncontrolled Trial. JAMA neurology. 2020 Jan 13;77(4):427-34. 
90. Bendikov-Bar I, Maor G, Filocamo M, Horowitz M. Ambroxol as a pharmacological chaperone for mutant glucocerebrosidase. Blood cells, molecules \& diseases. 2013 Feb;50(2):141-5.

91. Yang SY, Beavan M, Chau KY, Taanman JW, Schapira AHV. A Human Neural Crest Stem CellDerived Dopaminergic Neuronal Model Recapitulates Biochemical Abnormalities in GBA1 Mutation Carriers. Stem cell reports. 2017 Mar 14;8(3):728-42.

92. Fois $G$, Hobi $N$, Felder $E$, Ziegler $A$, Miklavc $P$, Walther $P$, et al. A new role for an old drug: Ambroxol triggers lysosomal exocytosis via $\mathrm{pH}$-dependent $\mathrm{Ca}(2)(+)$ release from acidic $\mathrm{Ca}(2)(+)$ stores. Cell calcium. 2015 Dec;58(6):628-37.

93. Fog CK, Zago P, Malini E, Solanko LM, Peruzzo P, Bornaes $C$, et al. The heat shock protein amplifier arimoclomol improves refolding, maturation and lysosomal activity of glucocerebrosidase. EBioMedicine. 2018 Dec;38:142-53.

94. Reczek D, Schwake M, Schroder J, Hughes H, Blanz J, Jin X, et al. LIMP-2 is a receptor for lysosomal mannose-6-phosphate-independent targeting of beta-glucocerebrosidase. Cell. 2007 Nov 16;131(4):770-83.

95. Do CB, Tung JY, Dorfman E, Kiefer AK, Drabant EM, Francke U, et al. Web-based genomewide association study identifies two novel loci and a substantial genetic component for Parkinson's disease. PLoS genetics. 2011 Jun;7(6):e1002141.

96. Rothaug M, Zunke F, Mazzulli JR, Schweizer M, Altmeppen H, Lullmann-Rauch R, et al. LIMP2 expression is critical for beta-glucocerebrosidase activity and alpha-synuclein clearance. Proceedings of the National Academy of Sciences of the United States of America. 2014 Oct 28;111(43):15573-8.

97. Zunke F, Andresen L, Wesseler S, Groth J, Arnold P, Rothaug M, et al. Characterization of the complex formed by beta-glucocerebrosidase and the lysosomal integral membrane protein type- 2 . Proceedings of the National Academy of Sciences of the United States of America. $2016 \mathrm{Apr}$ 5;113(14):3791-6.

98. Ysselstein D, Nguyen M, Young TJ, Severino A, Schwake M, Merchant K, et al. LRRK2 kinase activity regulates lysosomal glucocerebrosidase in neurons derived from Parkinson's disease patients. Nature communications. 2019 Dec 5;10(1):5570.

99. Lu J, Yang C, Chen M, Ye DY, Lonser RR, Brady RO, et al. Histone deacetylase inhibitors prevent the degradation and restore the activity of glucocerebrosidase in Gaucher disease. Proceedings of the National Academy of Sciences of the United States of America. 2011 Dec 27;108(52):21200-5.

100. Yang C, Rahimpour S, Lu J, Pacak K, Ikejiri B, Brady RO, et al. Histone deacetylase inhibitors increase glucocerebrosidase activity in Gaucher disease by modulation of molecular chaperones. Proceedings of the National Academy of Sciences of the United States of America. 2013 Jan 15;110(3):966-71. 